\title{
Integrated analysis of methylation-driven genes and pretreatment prognostic factors in patients with hepatocellular carcinoma
}

\author{
Dongsheng He, Shengyin Liao, Lifang Cai, Weiming Huang, Xuehua Xie and Mengxing You* (D)
}

\begin{abstract}
Background: The potential reversibility of aberrant DNA methylation indicates an opportunity for oncotherapy. This study aimed to integrate methylation-driven genes and pretreatment prognostic factors and then construct a new individual prognostic model in hepatocellular carcinoma (HCC) patients.

Methods: The gene methylation, gene expression dataset and clinical information of HCC patients were downloaded from The Cancer Genome Atlas (TCGA) database. Methylation-driven genes were screened with a Pearson's correlation coefficient less than -0.3 and a $P$ value less than 0.05 . Univariable and multivariable Cox regression analyses were performed to construct a risk score model and identify independent prognostic factors from the clinical parameters of HCC patients. The least absolute shrinkage and selection operator (LASSO) technique was used to construct a nomogram that might act to predict an individual's OS, and then C-index, ROC curve and calibration plot were used to test the practicability. The correlation between clinical parameters and core methylation-driven genes of HCC patients was explored with Student's t-test.

Results: In this study, 44 methylation-driven genes were discovered, and three prognostic signatures (LCAT, RPS6KA6, and C5orf58) were screened to construct a prognostic risk model of HCC patients. Five clinical factors, including T stage, risk score, cancer status, surgical method and new tumor events, were identified from 13 clinical parameters as pretreatment-independent prognostic factors. To avoid overfitting, LASSO analysis was used to construct a nomogram that could be used to calculate the OS in HCC patients. The C-index was superior to that from previous studies $(0.75$ vs $0.717,0.676)$. Furthermore, LCAT was found to be correlated with $T$ stage and new tumor events, and RPS6KA6 was found to be correlated with T stage.
\end{abstract}

Conclusion: We identified novel therapeutic targets and constructed an individual prognostic model that can be used to guide personalized treatment in HCC patients.

Keywords: Hepatocellular carcinoma, Methylation-driven genes, Prognosis, Nomogram

\footnotetext{
* Correspondence: youmengxing_oncol@163.com

Department of Medical Oncology, The First Hospital of Putian, Teaching

Hospital, Fujian Medical University, Putian 351100, China
}

(C) The Author(s). 2021 Open Access This article is licensed under a Creative Commons Attribution 4.0 International License, which permits use, sharing, adaptation, distribution and reproduction in any medium or format, as long as you give appropriate credit to the original author(s) and the source, provide a link to the Creative Commons licence, and indicate if changes were made. The images or other third party material in this article are included in the article's Creative Commons licence, unless indicated otherwise in a credit line to the material. If material is not included in the article's Creative Commons licence and your intended use is not permitted by statutory regulation or exceeds the permitted use, you will need to obtain permission directly from the copyright holder. To view a copy of this licence, visit http://creativecommons.org/licenses/by/4.0/ The Creative Commons Public Domain Dedication waiver (http://creativecommons.org/publicdomain/zero/1.0/) applies to the data made available in this article, unless otherwise stated in a credit line to the data. 


\section{Background}

Liver cancer is the sixth most common cancer and was the third major cause of cancer-related death in 2018 [1]. Hepatocellular carcinoma (HCC), the most common type of primary liver cancer, is the fourth most commonly diagnosed cancers in men and the fourth leading causes of cancer-related death among both women and men in China; the global incidence of $\mathrm{HCC}$ is predicted to exceed a million cases per year by 2025 [2, 3]. Alcohol abuse, hepatitis $B$ virus or hepatitis $C$ virus infection are the main causes of $\mathrm{HCC}$. At present, surgical resection, ablative electrochemical therapies, chemoembolization, and radioembiolization are the most common treatments for HCC patients [4]. However, the 5-year survival rate of HCC patients remains poor due to intrahepatic spread and recurrence [5]. Therefore, exploring novel therapeutic targets and developing a prognosis module to guide personalized treatment are still needed.

Aberrant epigenetic changes could inappropriately inhibit or activate signaling pathways, which lead to the beginning of cancer. Epigenetic changes are considered to be a crucial step in the advancement of genetic alterations and the early stage of tumor progression [6]. DNA methylation, a covalent modification of the nucleotide cytosine at the $5^{\prime}$ position, is the most commonly studied epigenetic mechanism. DNA hypo- or hypermethylation could result in the occurrence of malignant tumors. DNA hypomethylation is considered to be an indication of cancer cells and affects chromosomal stability and activates oncogenes $[7,8]$. DNA hypermethylation is believed to contribute to decreased gene expression and transcriptional suppression [9]. DNA methylation is an important role in tumorigenesis, and drugs that target DNA methylation are being developed based on the characteristic that DNA methylation can potentially be reversed [10].

In the present study, we initially filtered methylationdriven genes with stricter standards, which provides a compelling foundation for the study. By using univariate and multivariate Cox analyses, a prognostic module was constructed to predict the risk score of prognosis in HCC patients, then internal and external validation were performed to assess the prognostic model. Next, we conducted univariate and multivariate Cox analyses to identify independent predictors from clinical factors, including risk score, in HCC patients. Moreover, we included more comprehensive clinical information compared to that provided in previous studies and utilized the least absolute shrinkage and selection operator (LASSO) algorithm to build a nomogram that could be used to predict an individual's OS. To our knowledge, there are no previous studies exploring the relationship between the OS of $\mathrm{HCC}$ patients and these clinical parameters. The $\mathrm{C}$-index, ROC curve and calibrate plot were used to validate that the nomogram is superior to that from previous studies. Moreover, Student's t-test was conducted to analyze the correlation between the core methylation-driven genes and clinical parameters in HCC patients.

\section{Methods \\ Patients and clinical data collection}

In the present study, mRNA sequencing and DNA methylation data of HCC patients were obtained from The Cancer Genome Atlas (TCGA; https://portal.gdc. cancer.gov/) database. RNA sequencing data included 374 HCC samples and 50 normal liver samples. DNA methylation data (Illumina Human Methylation $450 \mathrm{k}$ ) included 380 HCC samples and 50 normal liver samples. In addition, we downloaded the clinical information of HCC patients $(n=377)$ from the TCGA database.

\section{Identification of differentially methylated and expressed genes}

The limma package was used to screen the differentially methylated genes, and the edgeR package was used to identify the differentially expressed genes $[11,12]$. To improve the accuracy, the differential methylation level between HCC samples and normal liver samples $(\Delta \beta)$ greater than 0.1 , false discovery rate $(F D R)<0.05$, fold change $>1$ were used as the cutoff criteria to identify the differentially methylated genes, and FDR $<0.05$ and fold change $>2$ were used to identify differentially expressed genes.

\section{Identification of methylation-driven genes}

The match function was carried out to identify the hypermethylation-low expressed genes and hypomethylationhigh expressed genes. To further improve the creditability, a correlation coefficient less than -0.3 with a $P$ value less than 0.05 was used to screen the methylated-driven genes [13].

\section{Construction of the risk score predictive model}

To screen the methylation-driven genes related to OS, we matched survival data with follow-up more than 90 days and corresponding methylation-driven gene expression of 329 HCC patients. Univariate Cox proportional hazard analysis was utilized to filter methylation-driven genes related to $\mathrm{OS}(P<0.05)$, and the core candidate genes to construct the risk score predictive model were identified with multivariable logistic regression analysis $(\mathrm{P}<0.05)$. HCC patients were separated into high-risk and low-risk groups, and the K-M method was used to analyze the groups. Moreover, Receiver operating characteristic curves (ROC) for 1 year, 2 years and 3 years were performed to assess the prognostic model. 
Internal and external validation of the predictive model The 329 HCC patients were randomly separated into training and testing groups by"caret" package for internal validation of the predictive model [14]. K-M analysis and ROC curves for 1 year, 2 years and 3 years were conducted to assess internal validation. Moreover, the prognostic risk model was further validated in the liver cancer database (LIRI-JP) from International Cancer Genome Consortium (ICGC; https://dcc.icgc.org/) database, K-M analysis and ROC curves for 1 year, 2 years and 3 years were performed to assess the external validation.

\section{Integrated analysis of the risk score and clinical parameters in HCC patients}

To completely identify pretreatment-independent predictors in HCC patients, the inclusion criteria for clinical factors were as follows: 1) neoadjuvant treatment was not received before the operation; and 2) the follow-up time was more than 90 days. The clinical information (age, sex, race, BMI, HCC risk factors, and surgical method) and risk score of HCC patients $(n=243)$ were integrated according to the patient ID of $\mathrm{HCC}$ patients after excluding missing data. Then, univariate and multivariable Cox regression analyses were conducted to identify independent prognostic indicators from the 13 clinical parameters.

\section{The development and assessment of the nomogram}

To avoid overfitting, LASSO logistic regression was used to filter key factors from clinical factors and build a nomogram that could be used to predict an individual's
OS. C-index, ROC curve and calibration plot were used to weigh the prognostic ability of the nomogram.

\section{Correlation analysis between clinical factors and methylation-driven genes}

To further explore the correlation between the core methylation-driven genes that were selected to construct the risk score module and clinical factors that were screened by the LASSO algorithm, Student's t-test was conducted, and $P<0.05$ was considered statistically significant.

\section{Results}

Identification of methylation-driven genes

A total of 3751 highly expressed genes, 1081 lowly expressed genes (Fig. 1a), 977 hypermethylated genes and 2828 hypomethylated genes of HCC were extracted from the TCGA database (Fig. 1b), and 43 hypermethylationlow expressed genes and 210 hypomethylation-high expressed genes were identified (Fig. 2). Then, 44 methylation-driven genes were filtered with a correlation less than -0.3 and $P<0.05$, and the genes were identified to be negatively correlated with methylation level (Fig. 3).

\section{Construction of the risk score model}

To identify methylation-driven genes related to OS of HCC patients, survival data of 329 HCC patients and 44 methylation-driven gene expression were integrated, and C5orf58, LCAT, ADH1B, RPS6KA6, SFN and ZDBF2 were identified with univariate Cox regression analysis. The 6 methylation-driven genes were significantly related to the OS of HCC patients. To further explore the
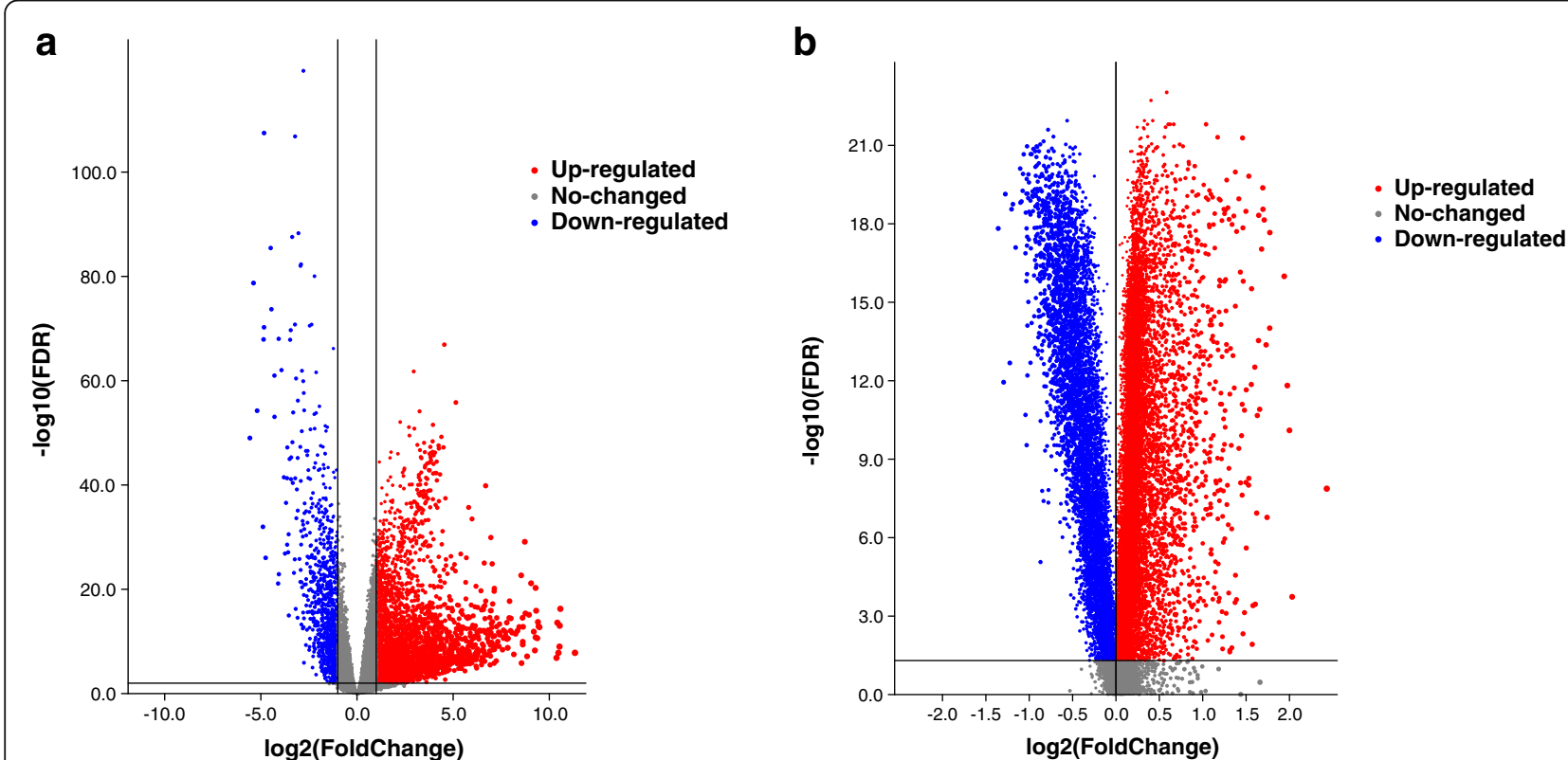

Fig. 1 Identification of differentially expressed and methylated genes in patients with hepatocellular carcinoma. a The highly expressed and lowly expressed genes in hepatocellular carcinoma. b The hypermethylated and hypomethylated genes in hepatocellular carcinoma 


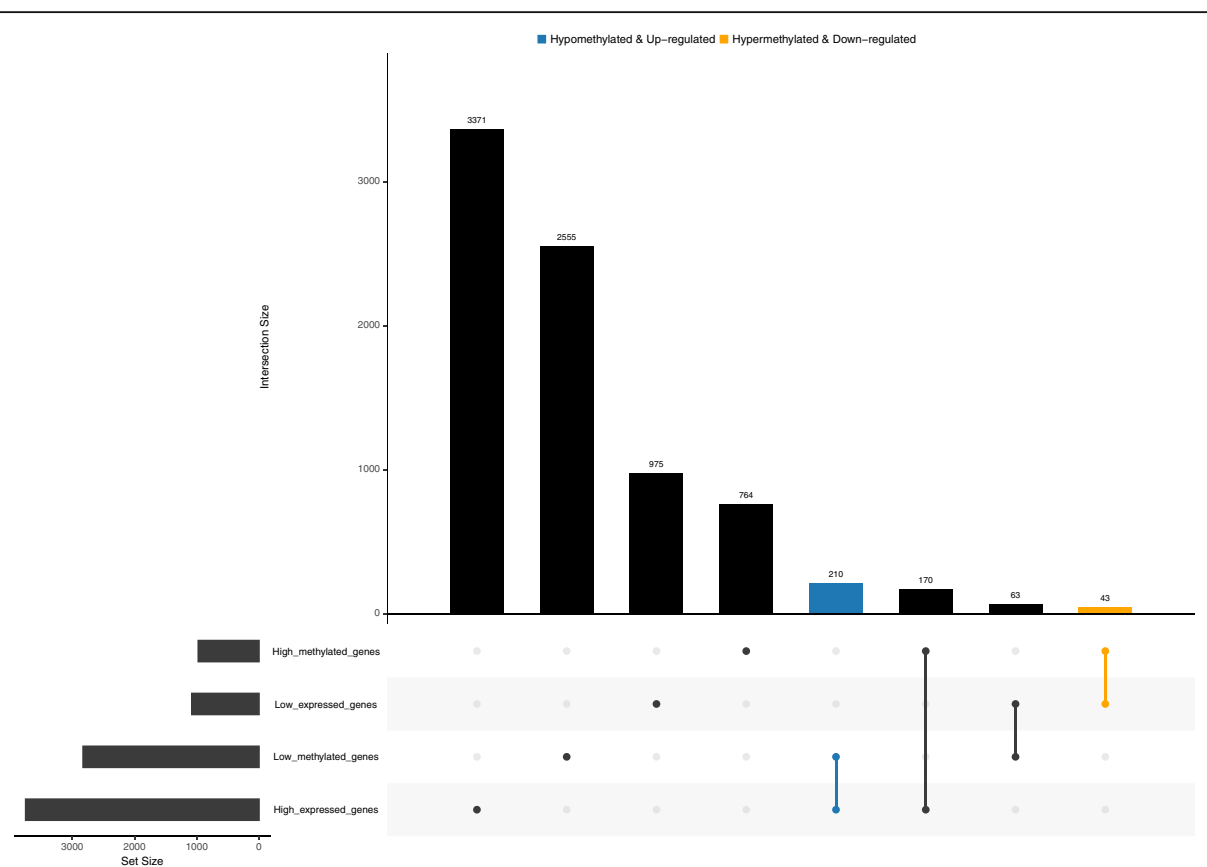

Fig. 2 The identification of methylation-driven genes in hepatocellular carcinoma. The blue bar represents low methylated and high expressed genes. The orange bar represents high methylated and low expressed genes

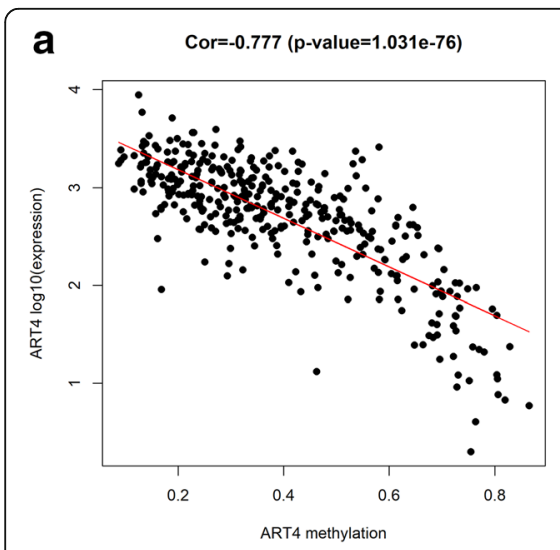

b

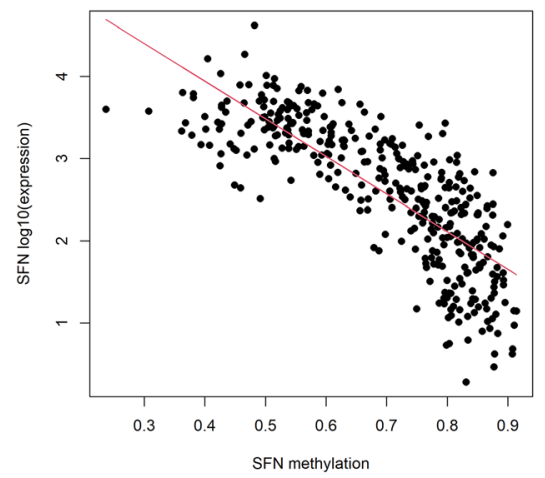

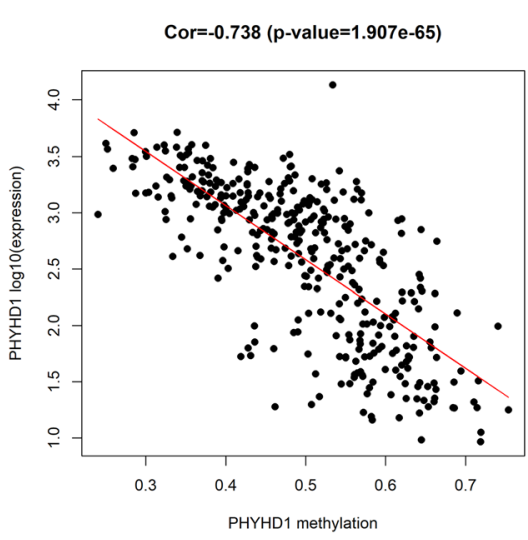

Cor=-0.706 (p-value=9.668e-58)

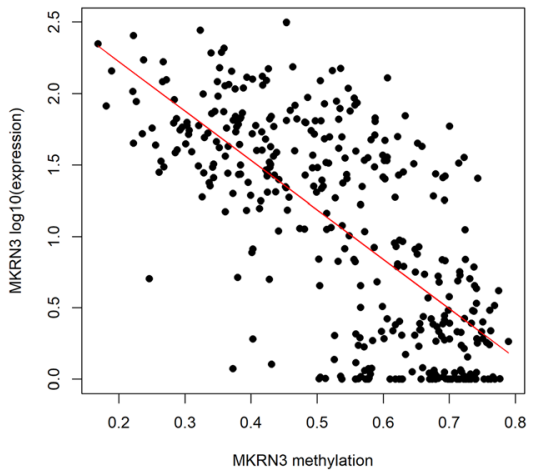

Cor $=-0.697(p-v a l u e=9.271 e-56)$

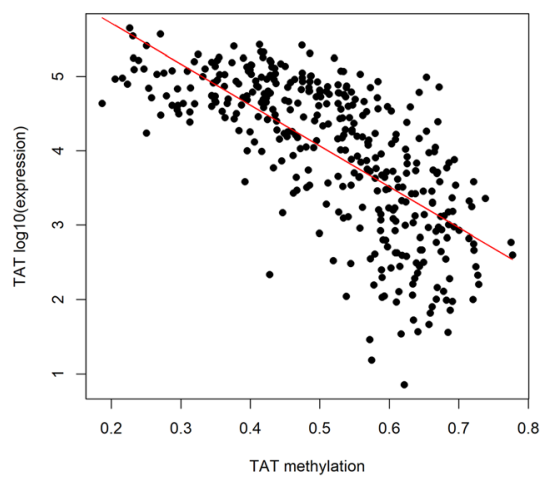

Cor $=-0.663(p-$ value $=1.107 e-48)$

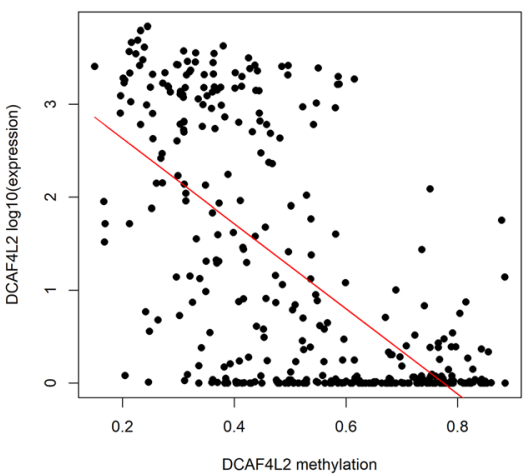

Fig. 3 Representative methylation-driven genes in hepatocellular carcinoma. a Correlation between DNA methylation and genes expression of top 3 hypermethylated genes. b Correlation between DNA methylation and genes expression of top 3 hypomethylated genes 

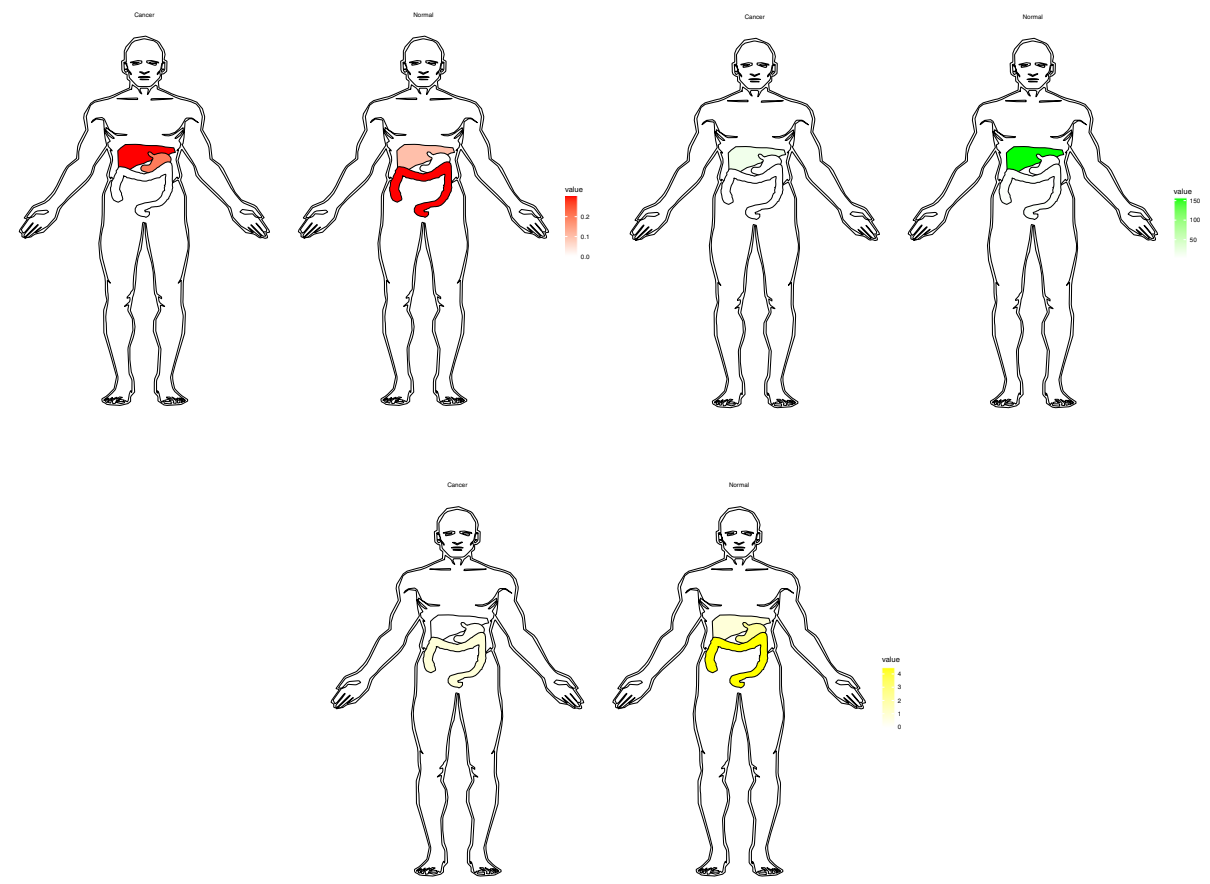

Fig. 4 Normal represent normal liver samples from TCGA database. Cancer represent HCC samples from TCGA database. The darker the color, the higher the degree of gene expression

independent predictive factor, multivariable Cox regression analysis was performed based on univariate Cox analysis, and C5orf58, LCAT, and RPS6KA6 were selected (Fig. 4). Then, the risk score module was completed after the coefficients of three genes were assigned by the Cox algorithm, as follows: risk score $=(0.001295 \times$ gene level of C5orf58) $+(-0.0001 \times$ gene level of LCAT $)+(0.002257 \times$ gene level of RPS6KA6). A total of 329 HCC patients were separated into high-risk and low-risk groups by the median risk score as the cutoff. The areas under the curves (AUC) in the prognostic model for 1 year, 2 years and 3 years were 0.742, 0.697 and 0.661, respectively (Fig. 5). The OS of the two groups was significantly different in K$\mathrm{M}$ analysis (Fig. 6).

\section{Internal and external validation of the predictive model}

The 329 HCC patients were randomly separated into training group and $(n=233)$ testing group $(n=96)$. As shown in Fig. 7a-b, the OS between high risk and low risk groups was significantly different in training and testing groups $(P=0.040 ; P=0.006)$. Meanwhile, the AUCs in training cohort for the 1 year, 2 years and 3 years were $0.720,0.654$ and 0.664 (Fig. 7c-e), the AUCs in testing cohort for 1 year, 2 years and 3 years were $0.815,0.821$ and 0.674 (Fig. 7f-h). Moreover, external validation also suggest the optimistic prognostic ability. The $P$ value of K-M analysis of the high-risk and lowrisk groups was 0.003 in ICGC database (Fig. 8a). The
AUCs for 1 year, 2 years and 3 years were $0.695,0.638$ and 0.655 , respectively (Fig. 8b-d).

\section{The identification of independent predictive indicators}

To further assess the independence of the risk score as a predictive factor in $\mathrm{HCC}$ patients, risk score, age, sex, grade, $\mathrm{T}$ stage, $\mathrm{BMI}$, race, other cancer, cancer state, HCC risk factor, surgical method, residual tumor, and new tumor events were integrated with survival information of HCC patients $(n=243)$ after excluding missing data, the characteristics of HCC patients were shown in Table 1. The 13 clinical parameters were included in univariate Cox regression analysis, and 5 clinical factors ( $\mathrm{T}$ stage, risk score, cancer status, surgical method and new tumor events) were filtered and found to be correlated with the OS of HCC patients (Table 2). Next, four independent predictors of HCC patients ( $\mathrm{T}$ stage, risk score, surgical method and new tumor events) were identified by the multivariable Cox regression algorithm (Table 3).

\section{The development and assessment of the nomogram}

To determine the effect of the clinical factors for HCC patients, 13 clinical characteristics were analyzed with the LASSO logistic regression algorithm. Seven clinical factors ( $\mathrm{T}$ stage, risk, BMI, cancer status, HCC risk factors, surgical method and new tumor events) were filtered (Fig. 9), from which a nomogram was built to predict an individual's 3- and 5-year OS rates (Fig. 10). 

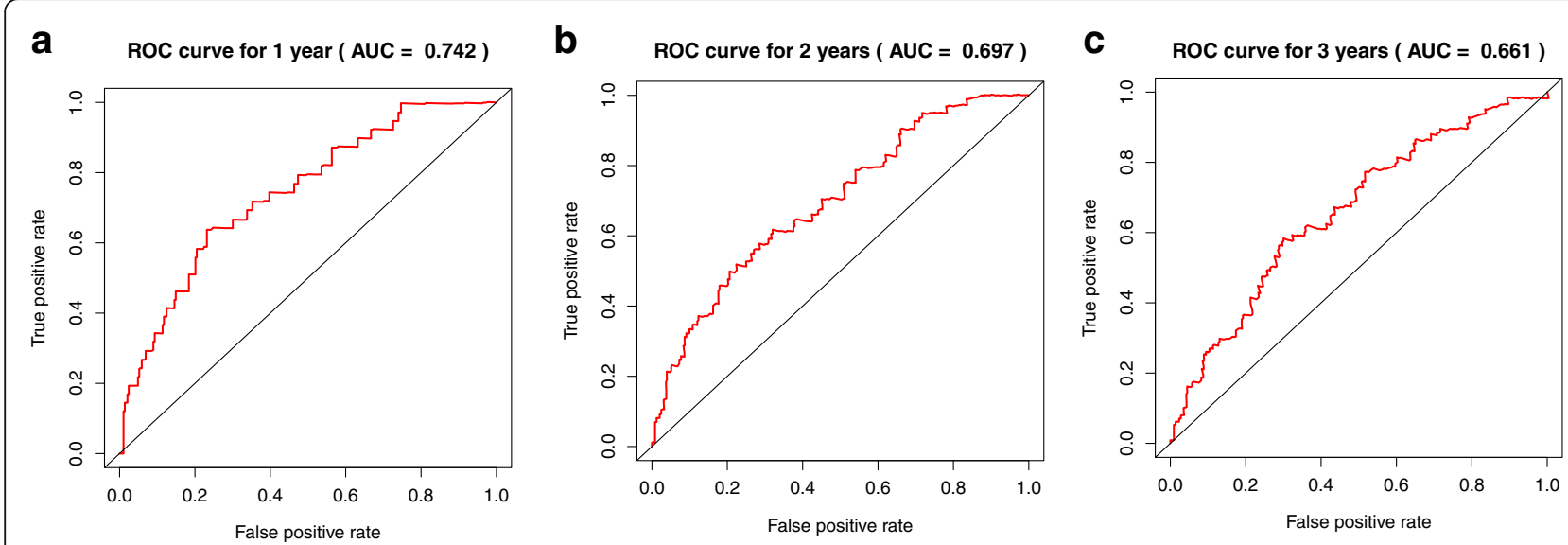

d

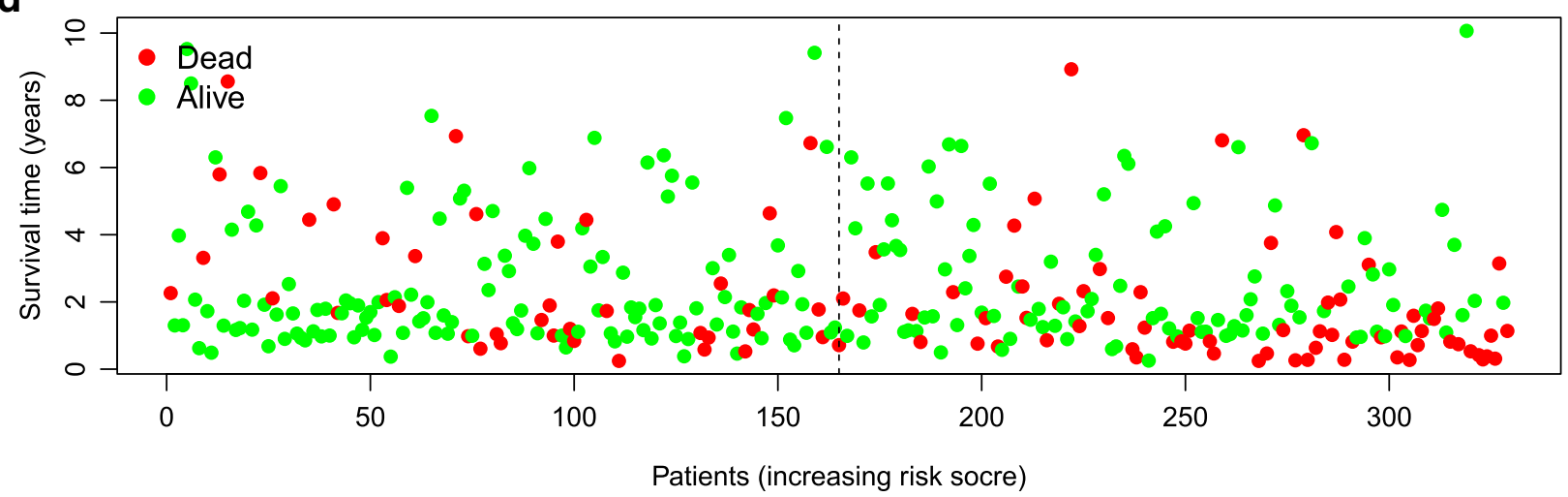

Fig. 5 Assessment of the prognostic model in HCC patients. a-c The AUCs of the prognostic model for 1 year, 2 years and 3 years. $\mathbf{d}$ Distribution of survival status based on the prognostic model in HCC patients

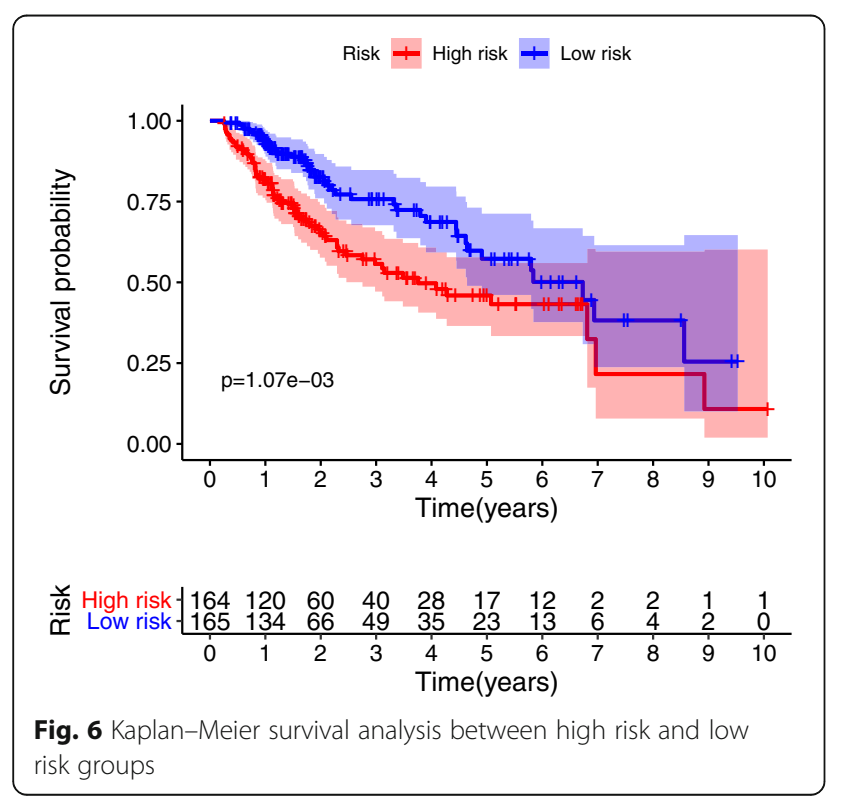

The reliability of the model was demonstrated by AUC (0.776, 0.791), C-index (0.75) and calibration plot (Fig. 11).

\section{Correlation analysis between clinical factors and methylation-driven genes}

For further analysis of the correlation between the clinical factors that were used to construct the nomogram and the selected methylation-driven genes, Student's t-test was performed. RPS6KA6 and LCAT were found to be correlated with $\mathrm{T}(P=0.015 ; P=0.042)$, and LCAT was significantly related to new tumor events $(P=0.028)$ (Fig. 12).

\section{Discussion}

Currently, the most common treatment for HCC patients is surgical operation. However, approximately half of HCC patients with hepatectomy experience recurrence within 3 years, even at stage A [15-18]. Furthermore, metastasis before diagnosis and incomplete resection for HCC patients further reduce the 5-year survival rate. To facilitate the identification of $\mathrm{HCC}$ 

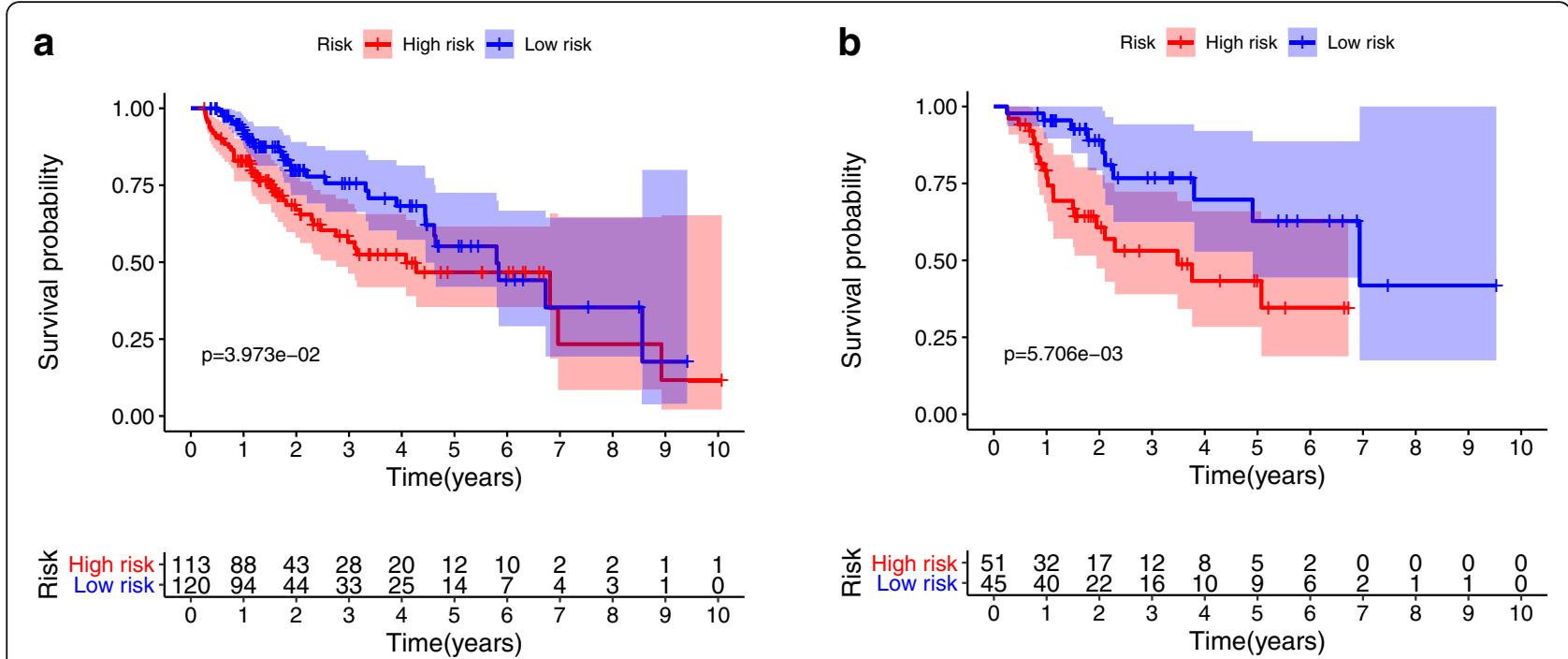

C ROC curve for 1 year $(A U C=0.720)$

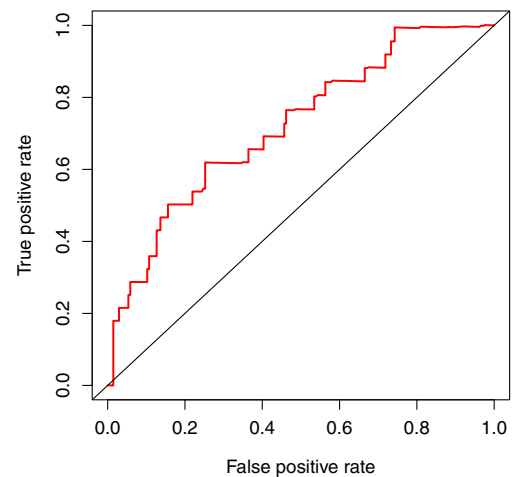

f ROC curve for 1 year $($ AUC $=0.815)$

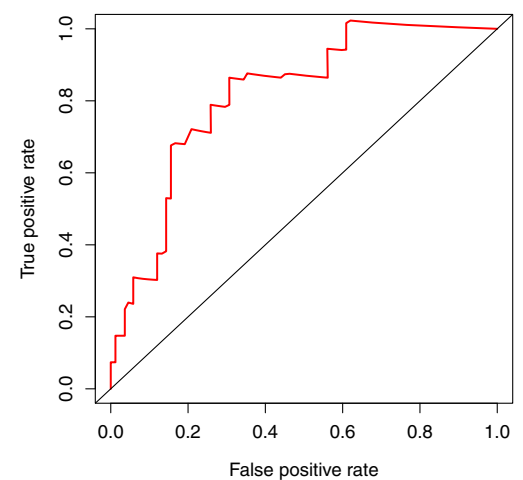

d ROC curve for 2 years $($ AUC $=0.654)$

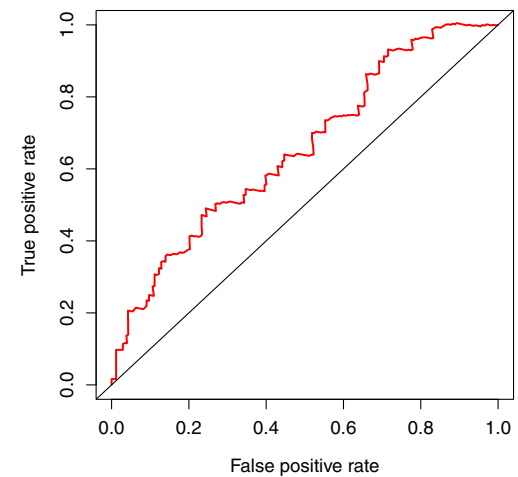

9 ROC curve for 2 years $($ AUC $=0.821)$

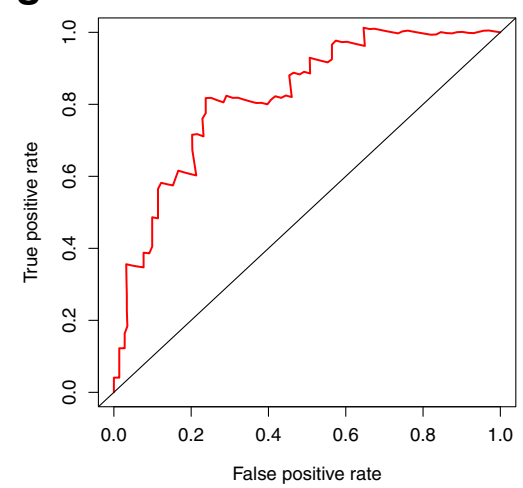

e ROC curve for 3 years $($ AUC $=0.664)$

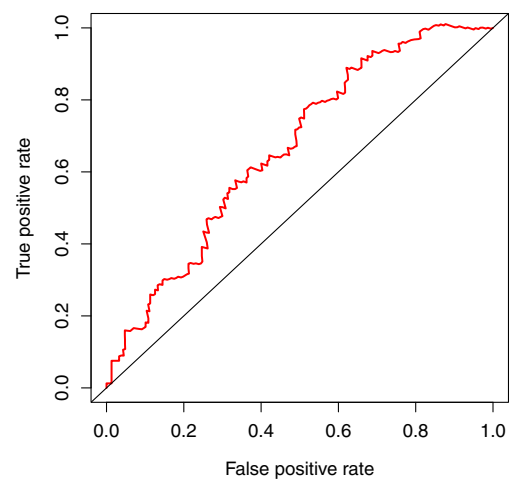

h ROC curve for 3 years ( AUC $=0.674$ )

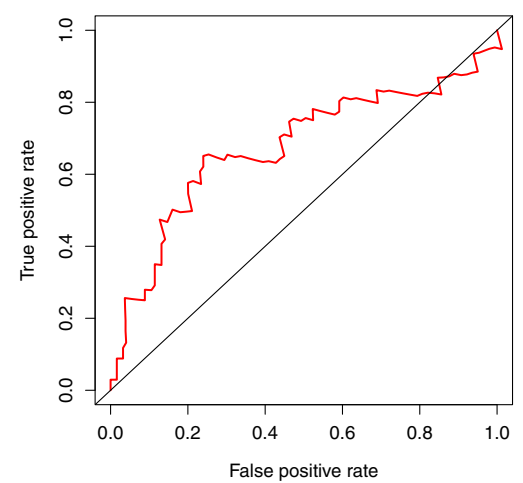

Fig. 7 Internal validation of the prognostic model in HCC. $\mathbf{a}$ and $\mathbf{b}$ The K-M analysis of the training cohort and testing cohort. c-e ROC analysis of the training cohort at 1 year, 2 years and 3 years. $\mathrm{f}-\mathrm{h}$. ROC analysis of the testing cohort at 1 year, 2 years and 3 years

patients with poor prognosis and timely intervention implementation, the identification of predictors related to OS is urgent.

Based on the characteristic of the reversibility of DNA methylation, a large number of drugs for DNA methylation and demethylation are currently being researched.
Azacitidine (AZA), a hypomethylating agent, has been suggested to be beneficial to myelodysplastic syndromes (MDS) and acute myeloid leukemia (AML) patients [1921], and the drug is licensed for clinical treatment in the US, Europe and China. Our study used stricter criteria to identify methylation-driven genes and integrated 


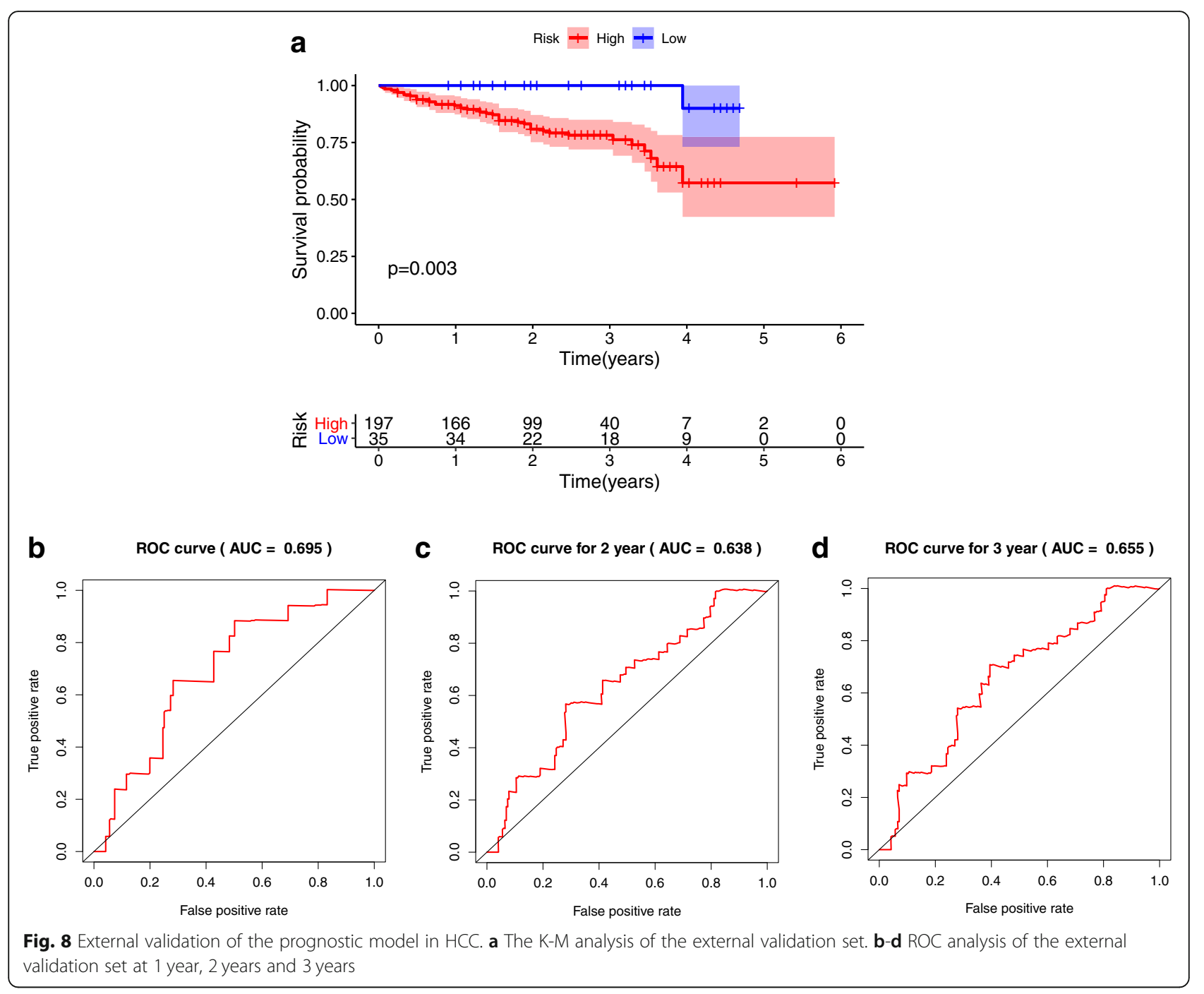

more comprehensive clinical information, including BMI, new cancer events, surgical method, cancer state, and HCC risk factors, to predict an individual's prognosis, which further improved the reliability of the study.

In this study, we tried to explore the biological targets of HCC that can be applied by methylation-targeted drugs. After differentially expressed genes and differentially methylated genes were identified, we found more hypomethylated genes than hypermethylated genes (2828 vs 977) and more highly expressed genes than lowly expressed genes (1821 vs 1493). Interestingly, the numbers of hypomethylated genes and highly expressed genes were greater than those in the control group, which is roughly consistent with the fact that methylation is negatively correlated with gene expression. Univariate and multivariable Cox regression analyses filtered three independent predictive genes. The high-risk group and low-risk group were separated into HCC patients using the three central methylation-driven genes. In this study,
LCAT was expressed at low levels and hypermethylated in HCC samples. Lecithin-cholesterol acyltransferase (LCAT) is an important gene that is correlated with poor prognosis in many cancers, such as ovarian cancer [22], Hodgkin lymphoma [23], and breast cancer [24]. LCAT is related to fatty metabolism in males, and its activity is reduced in patients with liver disease [25]. Ribosomal protein S6 kinase A6 (RPS6KA6) is a protein in the $90-\mathrm{kDa}$ ribosomal protein S6 kinase (RSK) family that participates in a series of cellular biological processes, such as cellular survival, proliferation, differentiation, mobility, nuclear signaling and protein synthesis [26-28]. RPS6KA6 plays a differential role in cancers and was reported to be an oncogene in lung squamous cell carcinoma and renal cell carcinoma $[29,30]$. In contrast, RPS6KA6 works as a tumor suppressor in endometrial cancer, acute myeloid leukemia, ovarian cancer, and breast cancer [31-34]. Furthermore, the low expression of RPS6KA6 was the result of DNA hypermethylation in endometrial cancers [31]. However, 
Table 1 Clinial characteristics of screened HCC patients

\begin{tabular}{|c|c|}
\hline parameters & patients, $\mathrm{n}(\%)$ \\
\hline \multicolumn{2}{|l|}{ Age (years) } \\
\hline$<60$ & $163(67.1 \%)$ \\
\hline$>=60$ & 80 (32.9\%) \\
\hline \multicolumn{2}{|l|}{ Gender } \\
\hline Female,n(\%) & 69 (28.4\%) \\
\hline Male,n(\%) & $174((71.6 \%)$ \\
\hline \multicolumn{2}{|l|}{ Grade } \\
\hline $1-2, n(\%)$ & $143(58.8 \%)$ \\
\hline $3-4, n(\%)$ & $100(41.2 \%)$ \\
\hline \multicolumn{2}{|l|}{ T grade } \\
\hline $\mathrm{T} 1-2, \mathrm{n}(\%)$ & $182(74.9 \%))$ \\
\hline T3-4,n(\%) & $61(25.1 \%)$ \\
\hline \multicolumn{2}{|l|}{ Risk score } \\
\hline Low,n(\%) & $123(50.6 \%)$ \\
\hline High,n(\%) & $120(49.4 \%)$ \\
\hline \multicolumn{2}{|l|}{ BMI } \\
\hline$<24, \mathrm{n}(\%)$ & 115 (47.3\%) \\
\hline$>=24, n(\%)$ & $128(52.7 \%)$ \\
\hline \multicolumn{2}{|l|}{ Race } \\
\hline Asian,n(\%) & $126(51.9 \%)$ \\
\hline Non-Asian,n(\%) & $117(48.1 \%)$ \\
\hline \multicolumn{2}{|l|}{ Other Tumor } \\
\hline No,n(\%) & $225(92.6 \%)$ \\
\hline Yes,n(\%) & $18(7.4 \%)$ \\
\hline \multicolumn{2}{|l|}{ Cancer status } \\
\hline Tumor Free,n(\%) & $162(66.7 \%)$ \\
\hline With Tumor,n(\%) & 81 (33.4\%) \\
\hline \multicolumn{2}{|l|}{ HCC risk factor } \\
\hline No,n(\%) & $55(22.6 \%)$ \\
\hline Yes,n(\%) & $188(77.4 \%)$ \\
\hline \multicolumn{2}{|l|}{ Surgical method } \\
\hline Lobectomy,n(\%) & 94 (38.7\%) \\
\hline Non-Lobectomy,n(\%) & $149(61.3 \%)$ \\
\hline \multicolumn{2}{|l|}{ Residual tumor } \\
\hline $\mathrm{RO}, \mathrm{n}(\%)$ & $230(94.7 \%)$ \\
\hline No R0,n(\%) & $13(5.3 \%)$ \\
\hline \multicolumn{2}{|l|}{ New tumor event } \\
\hline No,n(\%) & $105(43.2 \%)$ \\
\hline Yes,n(\%) & $138(56.8 \%)$ \\
\hline
\end{tabular}

the role of RPS6KA6 in HCC has not been reported in previous studies. In our study, RPS6KA6, is a hypermethylated and lowly expressed gene, was identified as a core methylation-driven gene correlated with prognosis in HCC patients. Consistent with RPS6KA6, chromosome 5
Table 2 Univariate COX regression analyses of clinicopathologic factors associated with OS

\begin{tabular}{lll}
\hline Parameters & $\begin{array}{l}\text { univariate analysis } \\
\text { HR(95\% Cl) }\end{array}$ & $\boldsymbol{P}$ value \\
\hline T stage & $2.845(1.768-4.580)$ & $<0.001$ \\
New tumor events & $5.222(2.584-10.555)$ & $<0.001$ \\
Cancer status & $2.460(1.519-3.982)$ & $<0.001$ \\
BMl & $0.680(0.424-1.090)$ & 0.109 \\
Risk score & $1.814(1.123-2.930)$ & 0.015 \\
HCC risk factors & $0.737(0.437-1.243)$ & 0.252 \\
Surgical method & $0.409(0.251-0.667)$ & $<0.001$ \\
Residual tumor & $1.415(0.513-3.899)$ & 0.502 \\
Race & $1.175(0.726-1.903)$ & 0.512 \\
Grade & $1.130(0.670-1.825)$ & 0.617 \\
Gender & $0.887(0.538-1.462)$ & 0.639 \\
Other tumor & $1.150(0.496-2.668)$ & 0.744 \\
Age & $0.933(0.567-1.536)$ & 0.785 \\
\hline
\end{tabular}

open reading frame 58 (C5orf58) was hypermethylated and expressed at low levels in HCC. However, the roles of C5orf58 have not been previously reported. C5orf58 maps on chromosome 5 at $5 \mathrm{q} 35.1$ according to Entrez Gene [35]. The roles of these three genes, especially RPS6KA6 and C5orf58, have not been sufficiently elucidated in HCC. Given the potentially reversible characteristic of DNA methylation, we filtered the three core methylationdriven genes to identify high-risk HCC patients, which might be therapeutic targets of epigenetic drugs and reduce the risk score of HCC patients.

There are several comprehensive studies related to methylation-driven genes in HCC. However, few studies have integrated clinical parameters and core methylation-driven genes in HCC. The advantage of the study was that stricter criteria were used to obtain more precise methylation-driven genes. Then, the prognosis module based on three genes was built, and the number of genes to build the module increased the feasibility and reduced the clinical cost. The expression, methylation and clinical data were retrieve from matched HCC patients, the feature strengthens the persuasiveness of the prognostic module based on the methylationdriven genes in HCC patients. The internal and

Table 3 Multivariate COX regression analyses of clinicopathologic factors associated with OS

\begin{tabular}{lll}
\hline Parameters & $\begin{array}{l}\text { Multivariate analysis } \\
\text { HR(95\% Cl) }\end{array}$ & $\boldsymbol{P}$ value \\
\hline T stage & $2.316(1.352-3.968)$ & 0.002 \\
New tumor events & $3.437(1.476-8.001)$ & 0.004 \\
Risk score & $1.948(1.151-3.296)$ & 0.013 \\
Surgical method & $0.519(0.302-0.890)$ & 0.017 \\
\hline
\end{tabular}



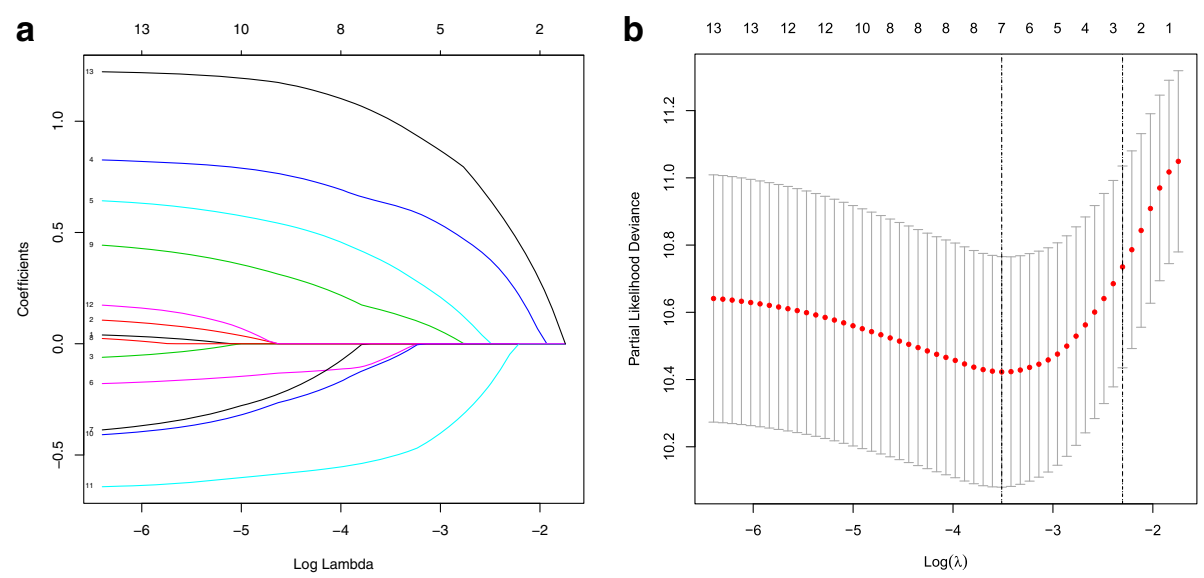

Fig. 9 a Distribution of least absolute shrinkage and selection operator (LASSO) coefficients for 13 clinical parameters. b Partial likelihood deviation of the LASSO coefficient distribution

external validation of the prognostic module also shown optimistic predictive capacities. Next, we first included more comprehensive clinical information than that included in previous studies to construct a nomogram and calculate an individual's prognosis. The nomogram to predict prognosis in $\mathrm{HCC}$ patients was more accurate than that in a previous study (C-index: 0.75 vs $0.717,0.676)$ [36, 37]. Furthermore, $T$ stage, new tumor event, surgical method and risk score were filtered to be the independent prognosticators, which further strengthens the result that risk score might be utilized to calculate the prognosis in $\mathrm{HCC}$ patients.
Finally, LCAT was found to be correlated with T stage and new tumor events, and RPS6KA6 was found to be related to $\mathrm{T}$ stage. It is worth further exploring whether the $\mathrm{T}$ stage and new cancer events were reversed by regulating LCAT and RPS6KA6. Overall, the nomogram, independent prognosticators and potential treatment targets are beneficial for individualized treatment of HCC patients.

Certainly, the potential limitations of the study should be noted. The biological mechanisms of LCAT, RPS6KA6 and C5orf58 remain to be explored. In addition, the study was based only on research data from the TCGA database,

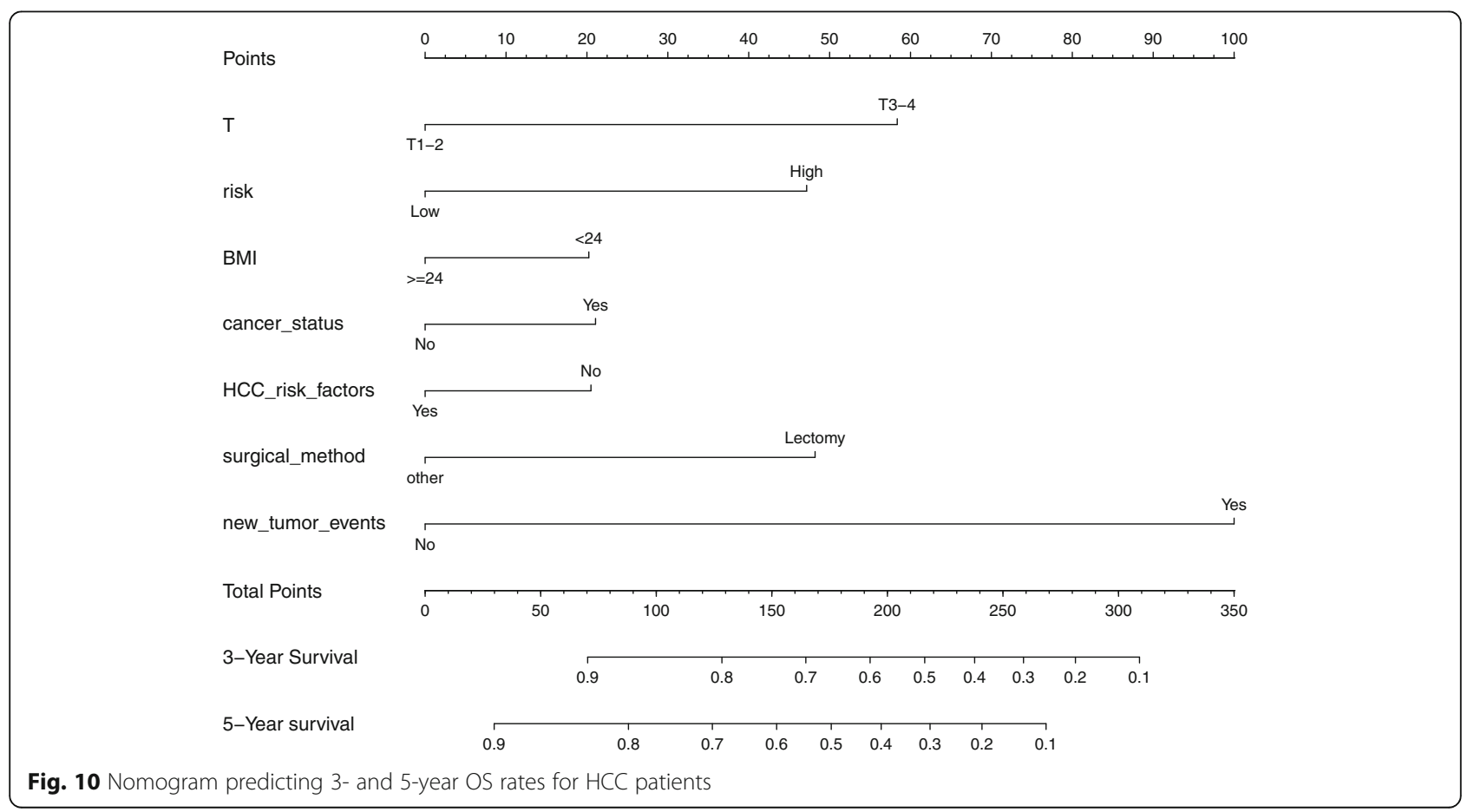




\section{a}

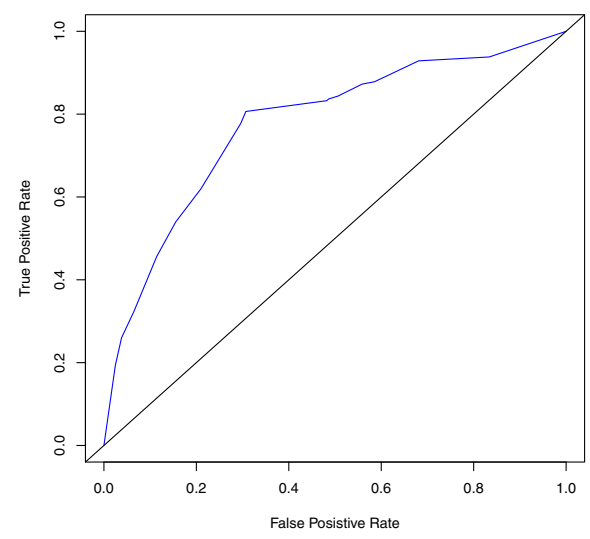

C

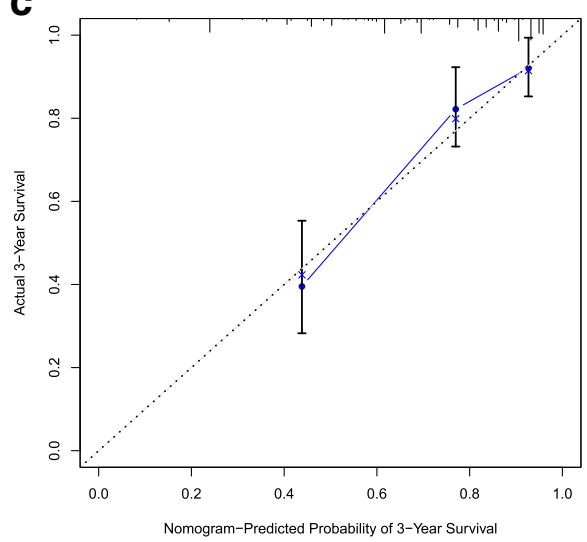

b

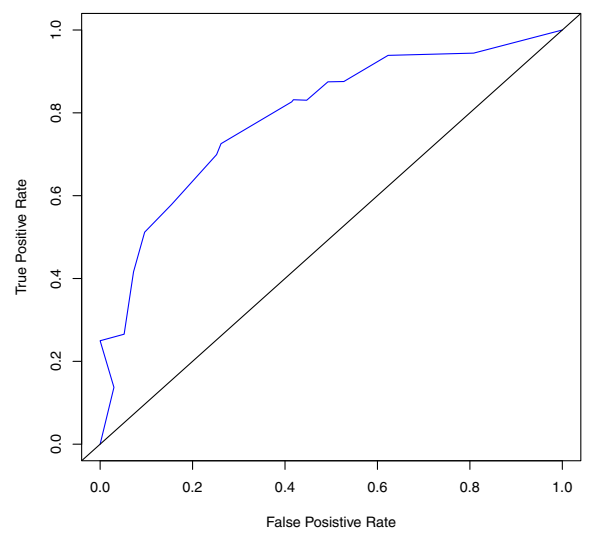

d

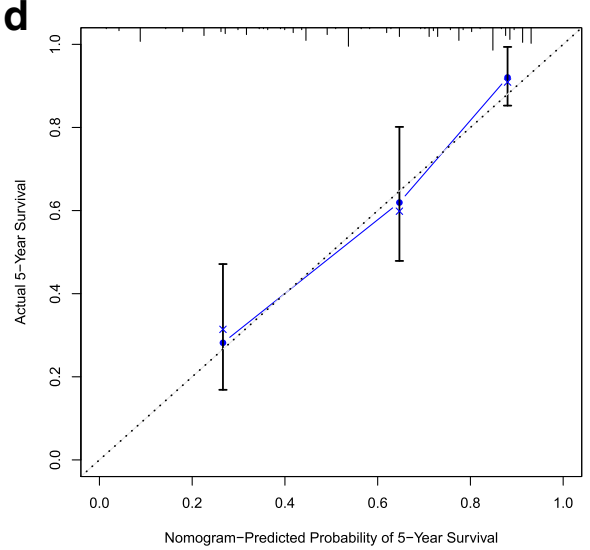

Fig. 11 a and b. 3- and 5-year ROC curves of the nomogram. c and d. 3- and 5-y survival calibration curves of the nomogram

which might contribute to selection bias. Therefore, a multicenter and large-scale study should be implemented to further validate our model.

\section{Conclusions}

In summary, a risk score module based on three core methylation-driven genes was developed, and it might be an independent predictor in HCC patients. In addition, we first included more comprehensive clinical information to construct the nomogram, which might be beneficial for predicting an individual's OS. Moreover, the independent predictors were identified from clinical parameters. Finally, core methylation-driven genes related to clinical parameters were demonstrated.

To the best of our knowledge, a risk score module and nomogram have been proposed for the first time, and it might be beneficial to explore potential therapeutic
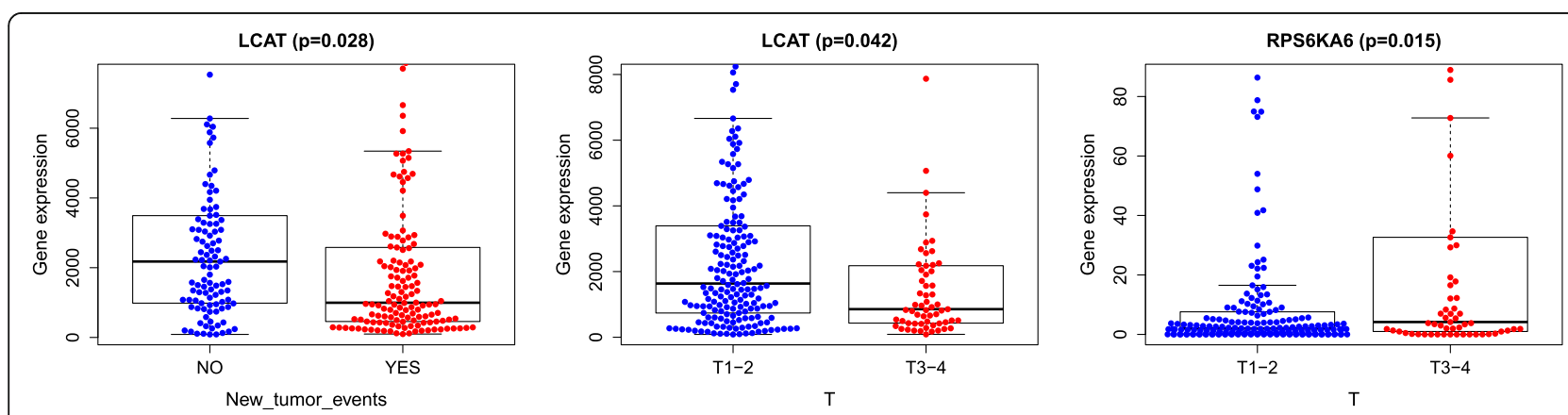

Fig. 12 correlation between clinical parameters and core methylation-driven genes. a correlation between LCAT and new tumor event. b correlation between LCAT and T stage. c. correlation between RPS6KA6 and T stage 
targets and develop individualized treatments for $\mathrm{HCC}$ patients.

\section{Abbreviations}

HCC: Hepatocellular carcinoma; TCGA: The Cancer Genome Atlas; LASSO: Least absolute shrinkage and selection operator; FDR: False discovery rate; MDS: Myelodysplastic syndromes; AML: Acute myeloid leukemia; ROC: Receiver operating characteristic curve; AUC: Areas under the curve

\section{Acknowledgments}

We thank the TCGA and ICGC Research Network who provided data for this study.

\section{Authors' contributions}

DSH designed, wrote and supervised the manuscript, LFC, WMH, and DSH performed the data analyses. XHX, MXY contributed significantly to process data. MXY and SYL supervised the study and revised the manuscript. All of the authors read and approved the final manuscript.

\section{Funding}

This work was supported by grants from the youth scientific research project of fujian provincial health and family planning commission (No. 2017-2-80), and the project of putian science and technology department (No. 2020SY006). The funding body had no role in the design of the study and collection, analysis, and interpretation of data and in writing the manuscript.

\section{Availability of data and materials}

The datasets used and analysed for this study were obtained from TCGA (https://portal.gdc.cancer.gov/) and ICGC (https://dcc.icgc.org/).

\section{Declarations}

Ethics approval and consent to participate

The sequencing and clinical data of this study are from TCGA and ICGC database, no ethics-related issues.

\section{Consent for publication}

Not applicable.

\section{Competing interests}

All authors declare they have no competing interests.

\section{Received: 19 October 2020 Accepted: 6 May 2021} Published online: 25 May 2021

\section{References}

1. International Agency for Research on Cancer, World Health Organization. Cancer today. https://gco.iarc.fr/today/home. Accessed 25 Aug 2020.

2. Chen W, Zheng R, Baade PD, Zhang S, Zeng H, Bray F, et al. Cancer statistics in China, 2015. CA Cancer J Clin. 2016;66(2):115-32. https://doi.org/10.3322/ caac. 21338

3. Ferlay J, Soerjomataram I, Dikshit R, Eser S, Mathers C, Rebelo M, et al. Cancer incidence and mortality worldwide: sources, methods and major patterns in GLOBOCAN 2012. Int J Cancer. 2015;136(5):E359-86. https://doi. org/10.1002/ijc.29210.

4. Hartke J, Johnson M, Ghabril M. The diagnosis and treatment of hepatocellular carcinoma. Semin Diagn Pathol. 2017;34(2):153-9. https://doi. org/10.1053/.jsemdp.2016.12.011.

5. Kulik L, El-Serag HB. Epidemiology and Management of Hepatocellular Carcinoma. Gastroenterology. 2019;156(2):477-91.e1.

6. Reis AH, Vargas FR, Lemos B. Biomarkers of genome instability and cancer epigenetics. Tumour Biol. 2016;37(10):13029-38. https://doi.org/10.1007/s132 77-016-5278-5

7. Kawano H, Saeki H, Kitao H, Tsuda Y, Otsu H, Ando K, et al. Chromosomal instability associated with global DNA hypomethylation is associated with the initiation and progression of esophageal squamous cell carcinoma. Ann Surg Oncol. 2014;21(Suppl 4):S696-702.

8. Ahuja N, Sharma AR, Baylin SB. Epigenetic therapeutics: a new weapon in the war against Cancer. Annu Rev Med. 2016;67(1):73-89. https://doi.org/1 0.1146/annurev-med-111314-035900.
9. Min HL, Kim J, Kim WH, Jang BG, Kim MA. Epigenetic silencing of the putative tumor suppressor gene GLDC (Glycine dehydrogenase) in gastric carcinoma. Anticancer Res. 2016;36(1):179-87.

10. Pan Y, Liu G, Zhou F, Su B, Li Y. DNA methylation profiles in cancer diagnosis and therapeutics. Clin Exp Med. 2018;18(1):1-14. https://doi.org/1 0.1007/s10238-017-0467-0.

11. Han L, Xu G, Xu C, Liu B, Liu D. Potential prognostic biomarkers identified by DNA methylation profiling analysis for patients with lung adenocarcinoma. Oncol Lett. 2018;15(3):3552-7. https://doi.org/10.3892/ol.2 018.7790 .

12. Li F, Li Q, Wu X. Construction and analysis for differentially expressed long non-coding RNAs and MicroRNAs mediated competing endogenous RNA network in colon cancer. PLoS One. 2018;13(2):e0192494. https://doi.org/1 0.1371/journal.pone.0192494

13. Zhang H, Dong S, Feng J. Epigenetic profiling and mRNA expression reveal candidate genes as biomarkers for colorectal cancer. J Cell Biochem. 2019; 120(6):10767-76. https://doi.org/10.1002/jcb.28368.

14. Zhang M, Wang X, Chen X, Zhang Q, Hong J. Novel immune-related gene signature for risk stratification and prognosis of survival in lower-grade Glioma. Front Genet. 2020;11:363. https://doi.org/10.3389/fgene.2020.00363.

15. Llovet JM, Fuster J, Bruix J. Intention-to-treat analysis of surgical treatment for early hepatocellular carcinoma: resection versus transplantation. Hepatology. 1999;30(6):1434-40. https://doi.org/10.1002/hep.510300629.

16. Shim JH, Jun MJ, Han S, Lee YJ, Lee SG, Kim KM, et al. Prognostic nomograms for prediction of recurrence and survival after curative liver resection for hepatocellular carcinoma. Ann Surg. 2015;261(5):939-46. https://doi.org/10.1097/SLA.0000000000000747.

17. Zhang ZM, Zhang YM, Yao F, Yi P, Huang S, Liu JY, et al. Analysis on postoperative efficacy of radical hepatectomy for patients with non-HBV/ HCV hepatocellular carcinoma. Asian Pac J Cancer Prev. 2015;16(8):3479-83. https://doi.org/10.7314/APJCP.2015.16.8.3479.

18. Tabrizian P, Jibara G, Shrager B, Schwartz M, Roayaie S. Recurrence of hepatocellular cancer after resection: patterns, treatments, and prognosis. Ann Surg. 2015;261(5):947-55. https://doi.org/10.1097/SLA. 0000000000000710

19. Fenaux P, Mufti GJ, Hellstrom-Lindberg E, Santini V, Finelli C, Giagounidis A, et al. Efficacy of azacitidine compared with that of conventional care regimens in the treatment of higher-risk myelodysplastic syndromes: a randomised, open-label, phase III study. Lancet Oncol. 2009;10(3):223-32. https://doi.org/10.1016/S1470-2045(09)70003-8.

20. Dombret H, Seymour JF, Butrym A, Wierzbowska A, Selleslag D, Jang $\mathrm{JH}$, et al. International phase 3 study of azacitidine vs conventional care regimens in older patients with newly diagnosed AML with $>30 \%$ blasts. Blood. 2015;126(3):291-9. https://doi.org/10.1182/blood-2015-01621664.

21. Döhner H, Dolnik A, Tang L, Seymour JF, Minden MD, Stone RM, et al. Cytogenetics and gene mutations influence survival in older patients with acute myeloid leukemia treated with azacitidine or conventional care. Leukemia. 2018:32(12):2546-57. https://doi.org/10.1038/s41375-018-0257-z.

22. Russell MR, Graham C, D'Amato A, Gentry-Maharaj A, Ryan A, Kalsi JK, et al. A combined biomarker panel shows improved sensitivity for the early detection of ovarian cancer allowing the identification of the most aggressive type II tumours. Br J Cancer. 2017;117(5):666-74. https://doi.org/1 0.1038/bjc.2017.199

23. Cooke AL, Morris J, Melchior JT, Street SE, Jerome WG, Huang R, et al. A thumbwheel mechanism for APOA1 activation of LCAT activity in HDL. J Lipid Res. 2018;59(7):1244-55. https://doi.org/10.1194/jlr. M085332.

24. Subbaiah PV, Liu M, Witt TR. Impaired cholesterol esterification in the plasma in patients with breast cancer. Lipids. 1997;32(2):157-62. https://doi. org/10.1007/s11745-997-0020-5.

25. Tahara D, Nakanishi T, Akazawa S, Yamaguchi Y, Yamamoto H, Akashi M, et al. Lecithin-cholesterol acyltransferase and lipid transfer protein activities in liver disease. Metabolism. 1993;42(1):19-23. https://doi.org/10.1016/00260495(93)90166-L.

26. Carriere A, Ray H, Blenis J, Roux PP. The RSK factors of activating the Ras/ MAPK signaling cascade. Front Biosci. 2008;13:4258-75. https://doi.org/10.2 741/3003.

27. Frödin $\mathrm{M}$, Gammeltoft S. Role and regulation of $90 \mathrm{kDa}$ ribosomal $\mathbf{S 6}$ kinase (RSK) in signal transduction. Mol Cell Endocrinol. 1999;151(1-2):65-77. https://doi.org/10.1016/S0303-7207(99)00061-1. 
28. Anjum R, Blenis J. The RSK family of kinases: emerging roles in cellular signalling. Nat Rev Mol Cell Biol. 2008;9(10):747-58. https://doi.org/10.1038/ nrm2509.

29. Fang YY, Ma FC, Gan XL, Luo WQ, He RQ, Xie HM, et al. Clinicopathological significance of ribosomal protein $\mathrm{S6}$ kinase A6 in lung squamous cell carcinoma: an immunohistochemical and RNA-seq study. Int J Clin Exp Pathol. 2018;11(3):1318-27.

30. Fan L, Li P, Yin Z, Fu G, Liao DJ, Liu Y, et al. Ribosomal s6 protein kinase 4: a prognostic factor for renal cell carcinoma. Br J Cancer. 2013;109(5):1137-46. https://doi.org/10.1038/bjc.2013.463.

31. Dewdney SB, Rimel BJ, Thaker PH, Thompson DM Jr, Schmidt A, Huettner P, et al. Aberrant methylation of the X-linked ribosomal S6 kinase RPS6KA6 (RSK4) in endometrial cancers. Clin Cancer Res. 2011;17(8):2120-9. https:// doi.org/10.1158/1078-0432.CCR-10-2668.

32. Rafiee M, Keramati MR, Ayatollahi H, Sadeghian MH, Barzegar M, Asgharzadeh A, et al. Down-regulation of ribosomal 56 kinase RPS6KA6 in acute myeloid leukemia patients. Cell J. 2016;18(2):159-64. https://doi.org/1 0.22074/cellj.2016.4310

33. Arechavaleta-Velasco F, Zeferino-Toquero M, Estrada-Moscoso I, Imani-Razavi FS, Olivares A, Perez-Juarez CE, et al. Ribosomal S6 kinase 4 (RSK4) expression in ovarian tumors and its regulation by antineoplastic drugs in ovarian cancer cell lines. Med Oncol. 2016;33(2):11. https://doi.org/10.1007/ s12032-015-0724-6.

34. Thakur A, Sun Y, Bollig A, Wu J, Biliran H, Banerjee S, et al. Anti-invasive and antimetastatic activities of ribosomal protein $\$ 6$ kinase 4 in breast cancer cells. Clin Cancer Res. 2008:14(14):4427-36. https://doi.org/10.1158/10780432.CCR-08-0458.

35. Maglott D, Ostell J, Pruitt KD, Tatusova T. Entrez gene: gene-centered information at NCBI. Nucleic Acids Res. 2011;39(Database issue):D52-7 https://doi.org/10.1093/nar/gkq1237.

36. Li GX, Ding ZY, Wang YW, Liu TT, Chen WX, Wu JJ, et al. Integrative analysis of DNA methylation and gene expression identify a six epigenetic driver signature for predicting prognosis in hepatocellular carcinoma. J Cell Physiol. 2019;234(7):11942-50. https://doi.org/10.1002/jcp.27882.

37. Wang Y, Ruan Z, Yu S, Tian T, Liang X, Jing L, et al. A four-methylated mRNA signature-based risk score system predicts survival in patients with hepatocellular carcinoma. Aging. 2019;11(1):160-73. https://doi.org/10.1 8632/aging.101738.

\section{Publisher's Note}

Springer Nature remains neutral with regard to jurisdictional claims in published maps and institutional affiliations.

Ready to submit your research? Choose BMC and benefit from:

- fast, convenient online submission

- thorough peer review by experienced researchers in your field

- rapid publication on acceptance

- support for research data, including large and complex data types

- gold Open Access which fosters wider collaboration and increased citations

- maximum visibility for your research: over $100 \mathrm{M}$ website views per year

At $\mathrm{BMC}$, research is always in progress.

Learn more biomedcentral.com/submissions 